\title{
An Evaluation of Yoga and Meditation to Improve Attention, Hyperactivity, and Stress in High-School Students
}

\author{
Kirti Saxena, MD, Christopher D. Verrico, PhD, Johanna Saxena, BS, BA, \\ Sherin Kurian, MD, Stefanie Alexander, MD, $\mathrm{PhD}_{1}^{2}$ Ramandeep Singh Kahlon, MD, \\ Ruchir P. Arvind, MD, Adam Goldberg, MD, Nicholas DeVito, BA, Mirza Baig, BS, \\ Anastasia Grieb, BS, Jafar Bakhshaie, MD, PhD, Alessio Simonetti, MD, PhD, ${ }^{1,4}$ \\ Eric A. Storch, PhD, Laurel Williams, DO, and Lex Gillan, BS ${ }^{5}$
}

\begin{abstract}
Objective: Problems with attention and stress are common in children and predict academic difficulties and other behavioral and emotional problems. Mind-body interventions such as yoga and meditation improve attention and reduce stress. In this study, we examined the impact of Hatha yoga on attention and stress in ninth graders.

Design: A total of 174 ninth graders from a Texas high school were enrolled in the study. Teachers assigned students to a yoga group (YG) or control group (CG) based on their class schedule. The YG participated in 25-min Hatha yoga classes twice weekly over 12 weeks $(n=123)$. The CG included 51 students. Student self-reports on measures of inattention and hyperactivity (the strengths and weaknesses of ADHD [attention-deficit/hyperactivity disorder] symptoms and normal behavior rating scale for ADHD) and stress (perceived stress scale) were obtained at baseline and at 12 weeks.

Results: There were no significant differences in baseline levels of inattention $(p=0.86)$, hyperactivity $(p=0.25)$, and perceived stress $(p=0.28)$ between the YG and CG. Regarding inattention scores, there was a significant interaction of group and time $(b=-1.09$, standard error $[\mathrm{SE}]=0.30, p<0.001)$. Pairwise $t$-tests showed a significant reduction in inattention for the $\mathrm{YG}(d=0.27)$ but a significant increase in inattention for the CG. Regarding hyperactivity, there was no significant interaction of group and time $(b=-0.43, \mathrm{SE}=0.26$, $p=0.1)$. Pairwise $t$-tests demonstrated a significant reduction in hyperactivity for the YG $(d=0.22)$, but not the CG. The interaction of group and time was not significant in predicting the slope of change in perceived distress $(b=-0.93, \mathrm{SE}=1.19, p=0.43)$. Pairwise $t$-tests did not show a significant reduction in perceived distress for either group.
\end{abstract}

Conclusion: These findings suggest that Hatha yoga may improve attention and hyperactivity in high school students.

Keywords: yoga, high school students, attention, hyperactivity, stress

\footnotetext{
${ }^{1}$ Department of Psychiatry and Behavioral Sciences, Baylor College of Medicine, Houston, TX, USA.

${ }^{2}$ Department of Psychiatry and Behavioral Sciences, Vanderbilt University Medical Center, Nashville, TN, USA.

${ }^{3}$ Department of Psychiatry, University of Texas Health-McGovern Medical School, Houston, TX, USA.

${ }^{4}$ Department of Neurology and Psychiatry, Sapienza University of Rome, Rome, Italy.

${ }^{5}$ Institute for Spirituality and Health, Houston, TX, USA
} 


\section{Introduction}

$\mathbf{T}$ HE CONCEPT OF A "COMPLETE EDUCATION" is gaining popularity within schools worldwide. With focus on social, emotional, and physical wellbeing together with academic achievement, children and adolescents can acquire lifelong tools and skills to improve attention capacity and manage stress. Mind-body interventions, which utilize physical postures, breathing exercises, relaxation techniques, and meditation practices, produce overall improvements in wellbeing. ${ }^{1-4}$

For thousands of years, yoga has been taught and practiced throughout the world in various forms with the ultimate goal being the union of mind, body, and spirit. ${ }^{5}$ The practice of yoga aims to develop and maintain good physical and mental health. ${ }^{6-9}$ The six branches of yoga include Raja, Bhakti, Jnana, Karma, Mantra, and Hatha yoga. Hatha yoga encompasses the practices of physical postures, breathing exercises, and meditation. ${ }^{5}$ Its goal was to develop strength and flexibility of the body, a calm and clear mind, and overall good health. ${ }^{10-12}$ In the West, Hatha yoga is the most popular practice. $^{13}$

Given the accessibility of yoga (i.e., can be offered without equipment) and its cost-effective nature (i.e., group format), schools are an ideal environment to incorporate this practice. Children spend most of their day at school, so yoga practice can be incorporated into the curriculum. ${ }^{3,14}$ There are over 36 yogabased programs utilized in more than 940 schools across the United States. Across programs, the length (i.e., number of weeks), number of sessions, session duration, and formality (i.e., school-based vs. self-motivated) vary. ${ }^{1,15}$ However, the common theme across programs include physical posturing, breathing exercises, relaxation techniques, and mindfulness practices.

Khalsa and Butzer ${ }^{1}$ reviewed 47 yoga studies conducted in elementary, middle, and high schools primarily in India and the United States. Comparison across studies was not possible as yoga interventions differed in length, number of sessions, session duration, and curricula across schools-from formal curricula to instructors creating their own. Furthermore, the methodological quality was low to moderate; there were often small sample sizes and a lack of control group. Yet, the implemented yoga classes have yielded both positive and negative outcomes.

Serwacki and Cook-Cottone ${ }^{16}$ reviewed 12 quantitative school-based yoga studies and encountered similar methodological limitations. Yet, the school-based programs deemed beneficial for the students. Ferreira-Vorkapic et al. ${ }^{17}$ reported the usefulness of school-based yoga to be uncertain because of few randomized controlled trials, methodological concerns, small sample sizes, lack of control groups, varying yoga interventions taught, and varying duration of yoga sessions. They found that positive and negative outcomes often cancelled each other out.

Some studies suggest that yoga may improve inattention, and early intervention techniques that diminish attentiondeficit/hyperactivity disorder (ADHD) symptoms are important for favorable outcomes ${ }^{18}$; an 8-year longitudinal study ${ }^{19}$ revealed that lower school retention rates, failure to graduate secondary school, and lower level academic performance were accurately predicted by inattention and hyperactivity symptoms. Sethi et al. ${ }^{20}$ found that 60 low-income high school girls who participated in an integrated yoga module (IYM) for 5 days $^{21}$ had improved attention. Similarly, Sheela et al. ${ }^{22}$ found improvements in sustained attention in 66 university students who also practiced an IYM. Thus far, selfreported outcomes on inattention and hyperactivity in high school students participating in a school-based yoga intervention have not been studied.

In addition, the presence of life stressors are a consistent predictive factor for the emergence of mental health conditions. ${ }^{23,24}$ Given that many adults report the onset of their own mental health problems during childhood and adolescence, addressing these problems at a young age is particularly important. ${ }^{1,25}$

Positive findings have emerged suggesting that yoga may reduce stress. West et al. ${ }^{26}$ found significant reductions in perceived stress scores of 18 college students who practiced Hatha yoga compared with students who had participated in physical exercise. Among 14- to 15-year-old students in India, those students with lower stress scores and practiced yoga performed significantly better in academics. ${ }^{27}$

However, the current body of literature around schoolbased yoga is fewer than 20 years old, and is oftentimes inconclusive due to varying methodologies of studies. There is no consensus on dose of yoga intervention across age groups, fidelity of implementing the intervention, and the measurement of long-term outcomes. Even the highest quality studies yield both positive and negative results. ${ }^{17}$

The aim of this study was to determine the impact of a Hatha yoga and meditation intervention on self-reported measures of inattention, hyperactivity, and stress in ninth graders. We hypothesized that in comparison with students in the control arm, those receiving yoga for $25 \mathrm{~min}$ twice a week for 12 weeks would report improved inattention and hyperactivity and decreased stress.

\section{Methods}

\section{Study participants}

The local school district and the Institutional Review Board (IRB) at Baylor College of Medicine approved this study. The teachers assigned ninth graders to two groups, yoga group (YG) or control group (CG), and selected those students in the second-period health science class to participate in the YG. The yoga classes took place in the morning during the students' health science class, a required course for all ninth graders. The students enrolled in a health science class at a different time of day constituted the CG.

Every student received a parental consent and a child assent form that informed the minimal risks and that participation is voluntary. Each student read and signed the assent form demonstrating their own understanding of and willingness to participate in the study. Parents of each student read and signed the consent form to approve their child's participation in the study. Only those students with signed consent and assent forms were enrolled. In total, 184 students provided consent for the study. Demographics of our sample are given in Table 1. Of that group, 174 ninth-grade students completed the baseline and post measurements, with 123 students in the YG and 51 students in the CG.

\section{Hatha yoga intervention}

The yoga classes consisted of 25-min sessions of Hatha yoga and meditation, twice per week for 12 weeks. Each 
Table 1. Demographics

\begin{tabular}{lccc}
\hline & $\begin{array}{c}\text { Yoga group } \\
(\mathrm{N}=123), \\
\mathrm{n}(\%)\end{array}$ & $\begin{array}{c}\text { Control group } \\
(\mathrm{N}=51), \\
\mathrm{n}(\%)\end{array}$ & $\mathrm{p}$ \\
\hline Sex & & & \\
$\quad$ Female & $74(60.2)$ & $38(74.5)$ & 0.07 \\
$\quad$ Male & $49(39.8)$ & $13(24.5)$ & \\
Age (mean years $\pm \mathrm{SD})$ & $14.73 \pm 0.41$ & $14.84 \pm 0.47$ & 0.79 \\
Race & & & \\
$\quad$ Asian & $37(30)$ & $13(26)$ & 0.48 \\
$\quad$ African American & $22(18)$ & $14(27)$ & \\
$\quad$ Caucasian & $58(47)$ & $22(43)$ & \\
$\quad$ Other & $6(5)$ & $2(4)$ & \\
Ethnicity & & & \\
$\quad$ Hispanic or Latino & $43(35)$ & $18(36)$ & 0.90 \\
$\quad$ Not Hispanic & $80(65)$ & $32(64)$ & \\
$\quad$ or Latino & & & \\
\hline
\end{tabular}

$\mathrm{SD}$, standard deviation.

lesson consisted of $18 \mathrm{~min}$ of yoga poses and $7 \mathrm{~min}$ of meditation. The classes were led by a yoga instructor (L.G.) with 46 years of experience who was assisted by five yoga instructors. L.G. composed a 12-lesson curriculum intended for daily yoga and meditation practice during and outside class, which was provided to the YG in a written format. All the yoga instructors are nationally certified by L.G. and registered with the YogaALLIANCE at the Registered Yoga Teacher level $(200 \mathrm{~h})$ and the National Association of Certified Yoga Teacher $200 \mathrm{~h}$ level.

All yoga instructors followed the curriculum by L.G. However, the consistency in teachings was not objectively measured. Therefore, intervention fidelity data are lacking, which is a limitation to this study.

\section{Outcome measures}

One week before the beginning of the study and week 12 of the study, each student completed self-report questionnaires.

The strengths and weaknesses of ADHD symptoms and normal behavior rating scales. The strengths and weaknesses of ADHD symptoms and normal behavior (SWAN) is an 18-item questionnaire, consisting of two 9-item subscales: an inattentive subscale (IA; items 1-9) and a hyperactive/impulsive subscale (HI; items 10-18). The scores range from 0 to 18 (Refs. ${ }^{28,29}$ ). A score of six or greater on the IA indicates ADHD-inattentive type, the $\mathrm{HI}$ indicates ADHD-hyperactive/impulsive type, and both the IA and HI indicate ADHD-combined type.

The SWAN self-report was used in 2763 adolescents (1317 years) in a study at the Ontario Science Centre in Toronto, Canada, ${ }^{30}$ where self-report versions of the SWAN included the same 18 items, but with reference to "your child" instead of "me." High internal consistency of the SWAN has been reported, ${ }^{31,32}$ which was confirmed by this study. The SWAN-self in adolescents has good sensitivity and specificity for diagnosis, high internal consistency, and good convergence with the Conners-Wells' Adolescent Self-Report Scales. ${ }^{33}$
Perceived stress scale. The perceived stress scale (PSS) is a widely used instrument for measuring the perception of stress. This 10-item scale assesses the degree to which situations in one's life are appraised as stressful. Items tap into how unpredictable, uncontrollable, and overloaded respondents have found their lives within the past month. Scores on the PSS can range from 0 to 40: scores ranging from 0 to 13 are considered low stress, 14 to 26 moderate stress, and 27 to 40 high perceived stress. ${ }^{34}$ The PSS had sufficient internal reliability with a Cronbach's $\alpha$ of 0.68 . A mean composite of perceived stress was subsequently created. The scale has high internal consistency and test-retest reliability. ${ }^{34}$ Studies with children have used the PSS, but it is yet to be statistically validated in children. ${ }^{25,35-38}$

\section{Yoga and meditation questionnaire}

We created an IRB-approved self-assessment questionnaire for the yoga and meditation practice (Table 2), which was distributed after the 12-week intervention. Our aim was to understand which component of the practice the students most liked, so we divided the questionnaire into yoga and meditation practice.

\section{Data analyses}

Data analysis was conducted using SPSS version 24. First, data were examined for normality and presence of outliers. No outliers were detected, and none of the variables showed highly non-normal distributions. ${ }^{39}$ Next, sample descriptive statistics and a series of $t$-tests and chi-square tests were conducted to examine differences across the treatment groups regarding demographic characteristics and baseline levels of each dependent variable. The powers of these tests considering the sample size were all $>0.8$.

The primary statistical analyses included multilevel modeling with the scores on the scales/subscales of inattention, hyperactivity, and stress as the dependent variables, and time (baseline-1 week before classes started-and week 12) and group (YG vs. CG) as the two independent variables. The models included two levels, where repeated assessments across time (level 1; time) were nested within participants (level 2; group). The baseline levels of perceived stress were controlled for models with inattention and hyperactivity as dependent variables. The estimation of missing data in the models was based on restricted maximum-likelihood estimation. Satterthwaite approximation was used to calculate the degrees of freedom. ${ }^{40}$

Post hoc moderation analyses were also conducted to examine the moderator role of baseline levels of perceived

Table 2. Yoga and Meditation Questionnaire

Self-assessment questionnaire for yoga meditation and practice

1 Did yoga help you in any way? In a sentence, please tell us how yoga was helpful

2 How many times did you practice yoga at home?

3 Will you continue yoga?

4 Did meditation help you in any way? In a sentence, please tell us how meditation was helpful

5 How many times did you practice meditation at home? 6 Will you continue meditation? 
Table 3. Average Scores

\begin{tabular}{lrr}
\hline & \multicolumn{2}{c}{ Mean $( \pm$ SD $)$} \\
\cline { 2 - 3 } Variable & \multicolumn{1}{c}{ Baseline } & Week 12 \\
\hline Yoga & & \\
ADHD inattentiveness & $2.11( \pm 2.001)$ & $1.57( \pm 1.904)$ \\
ADHD hyperactive & $1.80( \pm 1.949)$ & $1.39( \pm 1.795)$ \\
PSS & $17.76( \pm 7.775)$ & $17.41( \pm 7.761)$ \\
Control & & \\
ADHD inattentiveness & $2.06( \pm 1.964)$ & $2.67( \pm 2.197)$ \\
ADHD hyperactive & $1.45( \pm 1.474)$ & $1.51( \pm 1.837)$ \\
PSS & $19.10( \pm 6.703)$ & $19.92( \pm 7.256)$ \\
\hline
\end{tabular}

ADHD, attention-deficit/hyperactivity disorder; PSS, perceived stress scale; SD, standard deviation.

stress for the effect of group membership on the slope of change in inattention and hyperactivity. Furthermore, the perceived helpfulness of yoga and meditation (a mean score derived from separate reports on yoga and meditation perceived helpfulness) and amount of yoga and meditation practice at home (a mean score derived from separate reports on yoga and meditation practiced at home) were examined as moderators of the relationships between the effect of time on inattention and hyperactivity, after controlling for baseline levels of perceived stress. Similar post hoc analyses were conducted for perceived stress as a dependent variable with no control variables. Cohen's $d^{41}$ was reported as estimates of effect size.

\section{Results}

Chi-square tests revealed no significant group differences in gender $(p=0.07)$, race, $(p=0.48)$, or ethnicity $(p=0.90)$.
A two-tailed $t$-test revealed no significant group difference in age $(p=0.79)$ (Table 1). The $t$-test comparisons did not show any significant differences regarding the baseline levels of inattention $(p=0.86)$, hyperactivity $(p=0.25)$, and perceived stress $(p=0.28)$ between the yoga and control groups. See Table 3 for average scores.

\section{Inattention and hyperactivity}

Regarding the change in the score of SWAN subscale of inattention, after controlling for baseline levels of perceived stress, there was a significant interaction of group and time $(b=-1.09$, standard error $[\mathrm{SE}]=0.30, p<0.001)$. Pairwise $t$-tests showed a significant reduction in inattention for YG $(t=3.239, p=0.002$; Cohen's $d=0.27)$ and a significant increase in inattention for the CG $(t=-2.574, p=0.013)$ (Fig. 1). Post hoc analysis did not show a significant moderator effect for perceived stress in the relationship $(b=-0.02, \mathrm{SE}=0.04, p=0.66)$. There was also no significant moderator effect for the perceived helpfulness and home practice of intervention for the effect of time on inattention within the YG $(b=0.32, \mathrm{SE}=0.61, p=0.59$, and $b=0.10, \mathrm{SE}=0.23, p=0.65$, respectively).

For predicting the change in the SWAN subscale of hyperactivity, after controlling for baseline levels of perceived stress, there was no significant interaction of group and time $(b=-0.43, \mathrm{SE}=0.26, p=0.1)$. Pairwise $t$-tests demonstrated a significant reduction in hyperactivity for the $\mathrm{YG}(t=2.670$, $p=0.009$; Cohen's $d=0.22)$, but not the CG $(t=-0.323$, $p=0.748$ ) (Fig. 2). Post hoc moderator analysis did not support the moderator role of perceived stress $(b=0.03$, $\mathrm{SE}=0.04, p=0.43)$. Neither perceived helpfulness nor home practice of intervention moderated the effect of time on hyperactivity within the YG group $(b=-0.14, \mathrm{SE}=0.56$, $p=0.79$, and $b=0.22, \mathrm{SE}=0.21, p=0.30$, respectively).

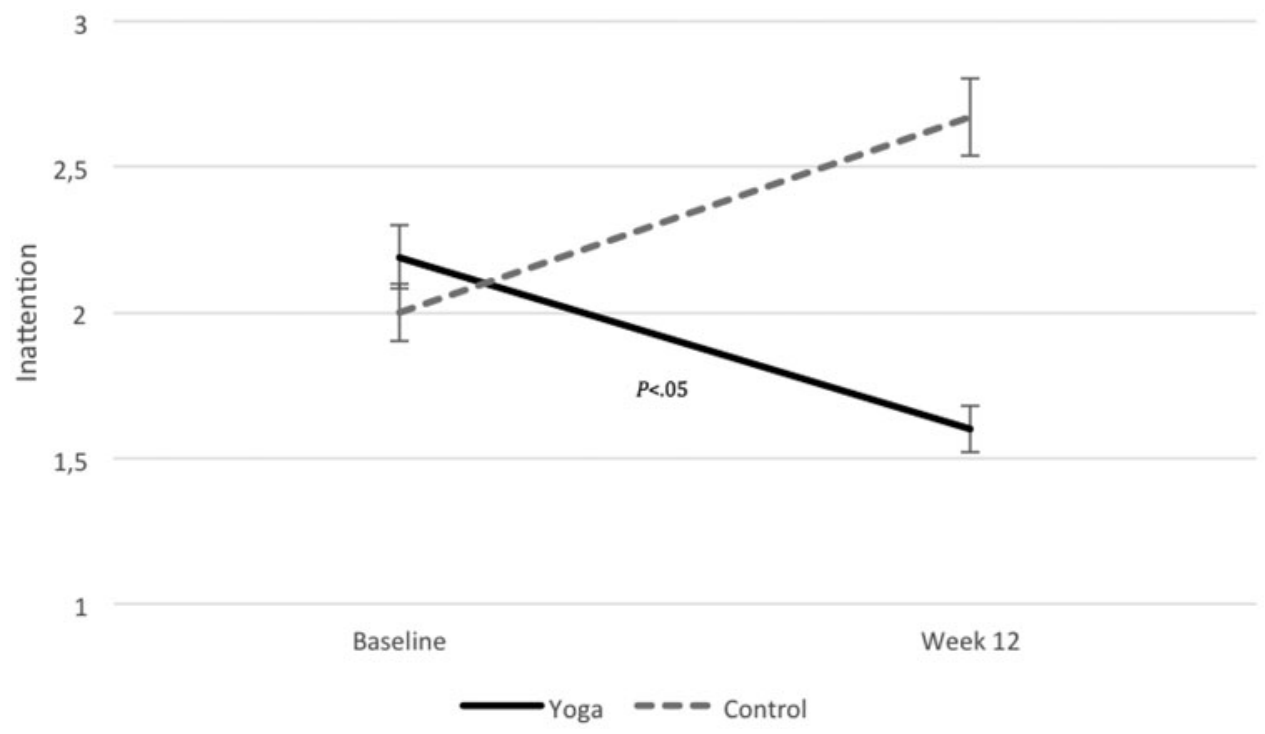

FIG. 1. SWAN rating scale for ADHD-inattention. At baseline, the average scores for the $Y G(2.11 \pm 2.001)$ and the CG $(2.06 \pm 1.964)$ were comparable $(p=0.86)$. At week 12 , the average scores of the YG $(1.57 \pm 1.904)$ and the CG $(2.67 \pm 2.197)$ were significantly different $(p<0.001)$. Within the YG, the average scores significantly decreased $(d=0.27)$. Within the CG, the average scores significantly increased $(p=0.013)$. ADHD, attention-deficit/hyperactivity disorder; CG, control group; SWAN, the strengths and weaknesses of ADHD symptoms and normal behavior; YG, yoga group. 
2,5

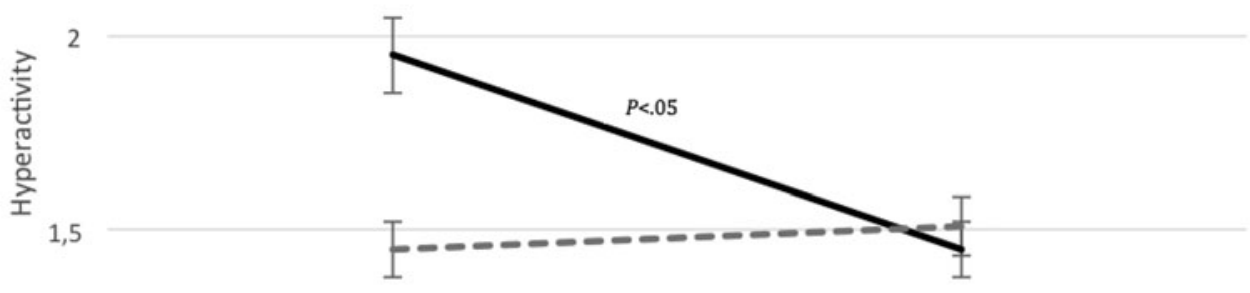

1

Baseline - Yoga - - Control
Week 12
FIG. 2. SWAN rating scale for ADHD-hyperactivity. At baseline, the average scores for the YG

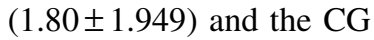
$(1.45 \pm 1.474)$ were not significantly different $(p=0.25)$. At week 12, the average scores of the YG $(1.39 \pm 1.795)$ decreased from baseline significantly $(d=0.22)$ and the CG average scores somewhat increased $(1.51 \pm 1.837)$. ADHD, attention-deficit/hyperactivity disorder; $\mathrm{CG}$, control group; SWAN, the strengths and weaknesses of ADHD symptoms and normal behavior; YG, yoga group.

\section{Perceived stress scale}

The interaction of group and time was not significant in predicting the slope of change in perceived stress $(b=-0.93$, $\mathrm{SE}=1.19, p=0.43)$. Pairwise $t$-tests did not show a significant reduction in perceived stress for either YG $(t=0.223$, $d f=118, p=0.824)$ or $\mathrm{CG}(t=-0.604, d f=49, p=0.549)$ (Fig. 3). Perceived helpfulness and home practice of intervention did not moderate the effect of time on change in perceived stress $(b=-1.11, \mathrm{SE}=1.90, p=0.56$, and $b=0.70$, $\mathrm{SE}=0.73, p=0.34$, respectively).

\section{Yoga and meditation questionnaire}

Eighty-seven students completed this questionnaire. The majority of students reported the practice of yoga $(65.5 \%$ of students) and meditation (74.1\% of students) to be helpful, stating it "gave them a chance to relax, calm down, and relieve stress." Further results of the survey are given in Tables 4 and 5.

\section{Discussion}

This 12-week study aimed to determine the effectiveness of 24 Hatha yoga sessions in improving attention and hyperactivity, and decreasing stress in ninth graders. Studies have reported benefits in high school students who practiced yoga for 10-18 weeks one to five times per week. This study design is within these parameters: high school students, 12week intervention conducted two to three times per week. ${ }^{42}$ Results from this study indicate reduced inattention and hyperactivity in those students who participated in the Hatha yoga practice in comparison with the students in the CG.

In this study, the PSS assessed students' stress levels before and after the Hatha yoga practice and, no significant differences were found over time or in comparison with the CG. The final yoga session and the rating scales were administered about 2 weeks before the end of semester examinations, which may have contributed toward no significant differences in the stress levels between the two groups. Other studies yielded similar results. For example, Noggle

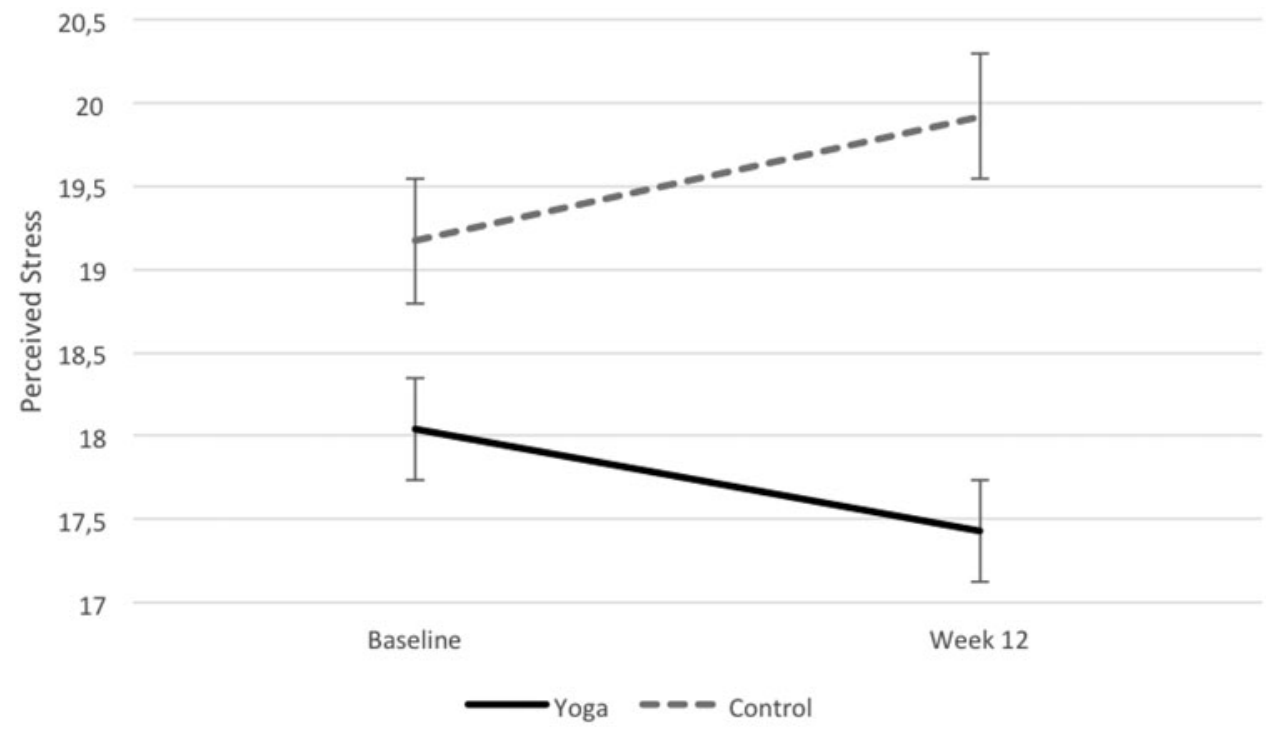

FIG. 3. Perceived stress. At baseline, the average scores for the YG (17.76 \pm 7.775$)$ and the CG $(19.10 \pm 6.703)$ were not significantly different $(p=0.28)$ At week 12, the YG scores somewhat decreased to $17.41 \pm 7.761$ and the $\mathrm{CG}$ somewhat increased to $19.92 \pm 7.256$. There was no significant difference found within or between groups. CG, control group; YG, yoga group. 
Table 4. Yoga and Meditation Perceived Helpfulness

\begin{tabular}{lccc}
\hline & $\begin{array}{c}\text { Yogawas } \\
\text { helpful }\end{array}$ & $\begin{array}{c}\text { Yoga was } \\
\text { NOT helpful }\end{array}$ & TOTALS \\
\hline Meditation was helpful & 49 & 16 & 65 \\
Meditation was & 8 & 14 & 22 \\
$\quad$ NOT helpful & 57 & 30 & 87 \\
\hline
\end{tabular}

et al. ${ }^{37}$ found no statistically significant differences in PSS scores between yoga $(n=36)$ and PE-as-usual $(n=15)$ groups after 28 sessions over 10 weeks. Khalsa et al. ${ }^{25}$ also did not find significant reductions in PSS scores in high school students (67 yoga and 33 controls) that participated in two to three yoga classes per week.

Potential reasons for different findings across studies are several. For instance, the frequency, amount, and duration of sessions across studies have differed. In addition, there is no standardized curriculum currently outlining what dose and for how long yoga needs to be taught for results to be deemed generalizable.

\section{Clinical significance}

Results from the SWAN self-report were not in the clinically significant range as none of the mean scores were above 6 (Table 3). Nonetheless, with the practice of Hatha yoga, inattention and hyperactivity symptoms diminished. In a clinical context, Hatha yoga, if practiced consistently, might be a tool that could delay or potentially prevent onset of a clinical diagnosis of ADHD.

This study was not designed for clinical outcomes, but can serve as a preliminary assessment of stress levels that may warrant clinical intervention. All our students' mean scores fell in the moderate stress range (Table 3). With the practice of Hatha yoga, the PSS scores from the YG did decrease, whereas the scores from the CG increased, but neither change was significant. Perhaps if their practice had been extended past 12 weeks, the decrease in stress levels may have reached significance.

\section{Limitations}

There are several limitations. First, students were not randomly assigned to groups. Second, students in the yoga group only participated in 25-min sessions. Most studies have reported benefits from longer sessions. In our case, $45 \mathrm{~min}$ were allotted for the yoga session, however the transit time between classes shortened the available time for yoga practice. Third, although it was emphasized that the

Table 5. Yoga and Meditation Continuation

\begin{tabular}{lccc}
\hline & $\begin{array}{c}\text { Will } \\
\text { continue } \\
\text { yoga }\end{array}$ & $\begin{array}{c}\text { Will NOT } \\
\text { continue } \\
\text { yoga }\end{array}$ & TOTALS \\
\hline $\begin{array}{l}\text { Will continue meditation } \\
\begin{array}{l}\text { Will NOT continue } \\
\text { meditation }\end{array}\end{array}$ & 26 & 20 & 46 \\
\begin{tabular}{l} 
TOTALS \\
\hline
\end{tabular} & 51 & 36 & 41 \\
\hline
\end{tabular}

yoga exercises should be practiced daily, there was no objective way that assessed whether this practice occurred. Fourth, objective ratings from teachers on student outcomes were not assessed. Finally, our yoga class size was about 50 students, whereas data from other studies suggest that smaller yoga classes (i.e., 10 or fewer students per class) yield improvements. ${ }^{43}$

\section{Conclusions}

Within these limitations, this study adds to the literature because it shows feasibility of a Hatha yoga practice in a school setting with positive outcomes for the students, particularly in improving inattention and hyperactivity. However, several important questions remain to be answered. Indeed, for the best possible benefits, the optimal dose for the yoga intervention and frequency and duration of practice still need to be determined. Furthermore, use of more objective outcomes including both symptomology and functional outcomes is needed. In summary, school is an ideal place to teach the practice of yoga. It is a skill and tool that can be incorporated into the daily routine of students to improve academic performance and mitigate stress.

\section{Acknowledgment}

The authors acknowledge the certified yoga instructors who taught the yoga curriculum to the students at the school.

\section{Author Disclosure Statement}

The authors declare that they have no conflicts of interest to disclose.

\section{Funding Information}

No funding was received for this article.

\section{References}

1. Khalsa SB, Butzer B. Yoga in school settings: A research review. Ann N Y Acad Sci 2016;1373:45-55.

2. Liehr P, Diaz N. A pilot study examining the effect of mindfulness on depression and anxiety for minority children. Arch Psychiatr Nurs 2010;24:69-71.

3. Zenner C, Herrnleben-Kurz S, Walach H. Mindfulnessbased interventions in schools-a systematic review and meta-analysis. Front Psychol 2014;5:603.

4. Beauchemin J, Manns J. Walking talking therapy. Ment Health Today 2008;8:34-35.

5. Iyengar BKS. Light on the Yoga Sutras of Patanjali. London: The Aquarian Press, 1993.

6. Cramer H, Lauche R, Langhorst J, et al. Is one yoga style better than another? A systematic review of associations of yoga style and conclusions in randomized yoga trials. Complement Ther Med 2016;25:178-187.

7. Feuerstein G. The Yoga Tradition: Its History, Literature, Philosophy and Practice. Prescott, AZ: Hohm Press, 1998: 550.

8. Cramer H, Lauche R, Dobos G. Characteristics of randomized controlled trials of yoga: A bibliometric analysis. BMC Complement Altern Med 2014;14:328.

9. Sharma M. Yoga as an alternative and complementary approach for stress management: A systematic review. J Evid Based Complementary Altern Med 2014;19:59-67. 
10. Burley M. Hatha Yoga: Its Context, Theory, and Practice. Delhi, India: Motilal Banarsidass Publishers Private Limited, 2000.

11. Hofmann SG, Andreoli G, Carpenter JK, et al. Effect of Hatha yoga on anxiety: A meta-analysis. J Evid Based Med 2016;9:116-124.

12. Uebelacker LA, Tremont G, Gillette LT, et al. Adjunctive yoga $\mathrm{v}$. health education for persistent major depression: A randomized controlled trial. Psychol Med 2017;47:21302142.

13. Riley D. Hatha yoga and the treatment of illness. Altern Ther Health Med 2004;10:20-21.

14. Weare K, Nind M. Mental health promotion and problem prevention in schools: What does the evidence say? Health Promot Int 2011;26(Suppl. 1):i29-i69.

15. Butzer B, Van Over M, Noggle Taylor JJ, et al. Yoga may mitigate decreases in high school grades. Evid Based Complement Alternat Med 2015;2015:259814.

16. Serwacki ML, Cook-Cottone C. Yoga in the schools: A systematic review of the literature. Int J Yoga Therap 2012: 101-109.

17. Ferreira-Vorkapic C, Feitoza JM, Marchioro M, et al. Are there benefits from teaching yoga at schools? A systematic review of randomized control trials of yoga-based interventions. Evid Based Complement Alternat Med 2015; 2015:345835.

18. Polderman TJ, Boomsma DI, Bartels M, et al. A systematic review of prospective studies on attention problems and academic achievement. Acta Psychiatr Scand 2010;122: 271-284.

19. Galera C, Melchior M, Chastang JF, et al. Childhood and adolescent hyperactivity-inattention symptoms and academic achievement 8 years later: The GAZEL Youth study. Psychol Med 2009;39:1895-1906.

20. Sethi JK, Nagendra HR, Sham Ganpat T. Yoga improves attention and self-esteem in underprivileged girl student. J Educ Health Promot 2013;2:55.

21. Nagarathna R, Nagendra H. Integrated Approach of Yoga Therapy for Positive Health. Bangalore: Swami Vivekananda Yoga Prakashana, 2008.

22. Sheela Nagendra HR, Ganpat TS. Efficacy of Yoga for sustained attention in university students. Ayu 2013;34: 270-272.

23. Anyan F, Hjemdal O. Adolescent stress and symptoms of anxiety and depression: Resilience explains and differentiates the relationships. J Affect Disord 2016;203:213-220.

24. Thapar A, Collishaw S, Pine DS, et al. Depression in adolescence. Lancet 2012;379:1056-1067.

25. Khalsa SB, Hickey-Schultz L, Cohen D, et al. Evaluation of the mental health benefits of yoga in a secondary school: A preliminary randomized controlled trial. J Behav Health Serv Res 2012;39:80-90.

26. West J, Otte C, Geher K, et al. Effects of Hatha yoga and African dance on perceived stress, affect, and salivary cortisol. Ann Behav Med 2004;28:114-118.

27. Kauts A, Sharma N. Effect of yoga on academic performance in relation to stress. Int J Yoga 2009;2:39-43.

28. Swanson JM, Kraemer HC, Hinshaw SP, et al. Clinical relevance of the primary findings of the MTA: Success rates based on severity of ADHD and ODD symptoms at the end of treatment. J Am Acad Child Adolesc Psychiatry 2001;40:168-179.
29. Swanson JM, Schuck S, Porter MM, et al. Categorical and dimensional definitions and evaluations of symptoms of ADHD: History of the SNAP and the SWAN rating scales. Int J Educ Psychol Assess 2012;10:51-70.

30. Burton CL, Wright L, Shan J, et al. SWAN scale for ADHD trait-based genetic research: A validity and polygenic risk study. J Child Psychol Psychiatry 2019;60:988-997.

31. Lai KY, Leung PW, Luk ES, et al. Validation of the Chinese strengths and weaknesses of ADHD-symptoms and normal-behaviors questionnaire in Hong Kong. J Atten Disord 2013;17:194-202.

32. Lakes KD, Swanson JM, Riggs M. The reliability and validity of the English and Spanish Strengths and Weaknesses of ADHD and Normal behavior rating scales in a preschool sample: Continuum measures of hyperactivity and inattention. J Atten Disord 2012;16:510-516.

33. Gurley J. Conners-Wells Adolescent Self Report Scale. In: Goldstein S, Naglieri JA, eds. Encyclopedia of Child Behavior and Development. Boston, MA: Springer, 2011.

34. Cohen S, Kamarck T, Mermelstein R. A global measure of perceived stress. J Health Soc Behav 1983;24:385-396.

35. Sarkissian M, Trent NL, Huchting K, et al. Effects of a Kundalini yoga program on elementary and middle school students' stress, affect, and resilience. J Dev Behav Pediatr 2018;39:210-216.

36. Eggleston B. The benefits of yoga for children in school. Int J Health Wellness Soc 2015;5:1-7.

37. Noggle JJ, Steiner NJ, Minami T, et al. Benefits of yoga for psychosocial well-being in a US high school curriculum: A preliminary randomized controlled trial. J Dev Behav Pediatr 2012;33:193-201.

38. Ramadoss R, Bose BK. Transformative life skills: Pilot studies of a yoga model for reducing perceived stress and improving self-control in vulnerable youth. Int J Yoga Ther 2010;20:75-80.

39. West SG, Finch JF, Curran PJ. Structural equation models with nonnormal variables: Problems and remedies. In: Hoyle RH, ed. Structural Equation Modeling: Concepts, Issues, and Applications. Thousand Oaks, CA: Sage Publications, Inc., 1995:56-75.

40. Satterthwaite FE. An approximate distribution of estimates of variance components. Biometrics 1946;2:110-114.

41. Cohen J. Statistical Power Analysis for Behavioral Sciences. New York, NY: Routledge Academic, 1988.

42. Hue M-T, Lau N-S. Promoting well-being and preventing burnout in teacher education: A pilot study of a mindfulness-based programme for pre-service teachers in Hong Kong. Teacher Development 2015;19:381-401.

43. Steiner NJ, Sidhu TK, Pop PG, et al. Yoga in an urban school for children with emotional and behavioral disorders: A feasibility study. J Child Family Stud 2012;22:815826.

Address correspondence to: Kirti Saxena, MD

Department of Psychiatry and Behavioral Sciences Baylor College of Medicine 8080 North Stadium Drive, Suite 180.35 Houston, TX 77054 USA

E-mail: kirti.saxena@bcm.edu 